\title{
O ENSINO DE FILOSOFIA NO ENSINO MÉDIO INTEGRADO
}

\author{
Admilson Eustáquio Prates, Edna Guiomar Salgado Oliveira, Jaciely Soares da Silva Soares \\ Silva, Leonardo Augusto Couto Finelli \\ Instituto Federal de Educação, Ciência e Tecnologia do Norte de Minais Gerais \\ DOI: $10.15628 /$ rbept.2019.9050
}

Artigo submetido em out/2019 e aceito em dez/2019

\begin{abstract}
RESUMO:
O objetivo deste texto é apresentar inicialmente um possível conceito de Filosofia e o seu ensino no Ensino Médio Integrado do Instituto Federal (IFs). Para tanto, nosso enfoque recai sobre cinco projetos de curso do Instituto Federal de Educação, Ciência e Tecnologia de Minas Gerais - Campus Bambuí. Nosso ponto de abordagem dá-se a partir de uma análise documental das ementas e da carga horária dessa disciplina, para, assim, evidenciar suas principais características, bem como conhecer qual o lugar de debate que a Filosofia ocupa na formação dos estudantes desta Instituição. Para tal, utilizaremos a metodologia comparativa, haja vista que essa nos permite, por meio da exploração das semelhanças e das diferenças documentais, identificar regularidades e transformações como defendido por Jordi Cais.
\end{abstract}

Palavras-chave: Filosofia. Ensino. Médio Integrado. Instituto Federal.

\section{THE TEACHING OF PHILOSOPHY IN INTEGRATED HIGH SCHOLL}

\begin{abstract}
:
The purpose of this paper is to initially present a possible concept of philosophy and its teaching in the Integrated High School of the Institutite Federal (IFs). To this end, our focus is on five course projects of the Federal Institute of Education, Science and Technology of Minas Gerais - Bambuí Campus. Our point of approach is based on a documentary analysis of the syllabys and workload of this discipline, in order to highlight its main characteristics, as well as to know the place of debate that Philosophy occupies in the formation of students of this institution. For this, we will use the comparative methodology, since it allows us, through the exploration of documentary similarities and differences, regularities and transformations as defended by Jordi Cais.
\end{abstract}

Keywords:

Philosophy. Teaching. Integrated High School. Federal Institute. 


\section{Introdução}

A filosofia, ainda hoje, se apresenta como um campo do saber envolto em constantes indagações, as quais vão desde questionamentos acerca dos seus objetos de estudo até questionamentos a respeito do seu campo metodológico de análise. Para além de questões voltadas para o campo propriamente dito, a filosofia também se apresenta, dentro do espaço escolar, como uma disciplina, tal como apontam e nos direcionam os Parâmetros Curriculares Nacionais (PCN's). Sobre essa disciplina, recai uma série de perguntas, que se agregam em: "o que ensinar?" e "como ensinar?". Tais questões não possuem respostas fechadas ou mesmo absolutas, mas se encontram, ainda, em um processo de construção.

Cientes disso, o texto aqui apresentado tem como um dos objetivos, em primeiro momento, conceituar o campo da filosofia. Propomos um diálogo entre filósofos, tais como Marilena Chauí, Platão e Sócrates, numa tentativa de construir dentro do campo filosófico, suas definições, problemas e objetivos. Posteriormente discutiremos acerca do Ensino de Filosofia, problematizando-o. Neste ponto de discussão, traremos para debate o questionamento: o Ensino de Filosofia ensina aos estudantes a Filosofia ou o filosofar? Tais questões ainda permeiam o campo do ensino, bem como causam ainda inquietude aos filósofos que se preocupam com o processo de ensino-aprendizagem na Educação e, no caso do nosso estudo específico, do Ensino de Filosofia no Ensino Médio.

Por último, e não menos importante, traçaremos uma linha de análise a partir de uma metodologia comparativa sobre as ementas dos cursos do Ensino Médio Integrado do Instituto Federal de Minas Gerais/Bambuí. Para tanto, deter-nos-emos nas propostas metodológicas de Jodis Cais (1997), o qual propõe que a metodologia comparativa tem, como uma de suas funções, buscar oferecer respostas a partir da comparação. Mesmo assim, detemo-nos a uma Instituição específica. Tal metodologia nos servirá para compararmos como as ementas dos cursos de informática, agropecuária, administração e manutenção automotiva pensam e organizam sistematicamente a ementa do Ensino de Filosofia.

Tais análises, além de apontarem para uma linha quase que idêntica para a disciplina, também nos revelou outra questão que futuramente caberá ser problematizada: "Em que lugar, as ementas de Filosofia do Instituto Federal contemplaram a discussão técnica e tecnológica tal como proposto pela legislação que institui os Institutos Federais?

\section{O campo da Filosofia}

Historicamente é reconhecido que a Filosofia nasce na Grécia entre os séculos VIII e VI a.c a partir de mudanças sociais, econômicas, culturais e políticas, como a invenção da política, a invenção da moeda, a invenção do calendário, a invenção da escrita, a invenção da polis e mudanças no 
comércio. Além disso, a estrutura da narrativa mítica ${ }^{1}$, que já apresentava elementos racionais e diferentes de outras narrativas míticas, possibilitou o invento do logos da demonstração e contraste com o logos da revelação. Isso não quer dizer que a Filosofia eliminou os mitos, pois a Filosofia e o saber mítico passam a coexistir onde cada um desses saberes apresentam uma perspectiva singular sobre o mundo e tudo o que ele nos oferece.

Dessa maneira, podemos entender que a Filosofia nasce como conhecimento racional dentro de um contexto específico da humanidade, apresentando questões e explicações pautadas não mais na narrativa mítica, e sim em uma razão que busca explicações na própria physis, isto é, que busca a unidade na multiplicidade. A Filosofia não se limitou a centrar seu olhar sobre as questões da cosmologia, mas ampliou-se para demandas e inquietações que envolvem o ser humano e as suas relações consigo mesmo e com os outros, ou seja, com a sociedade, a exemplo de questões políticas, éticas e educacionais.

A Filosofia é o conhecimento do não saber. É um saber que está entre a ignorância e a sabedoria. É um saber que não pertence aos deuses, tampouco aos sábios, e não permeia a existência dos ignorantes. No livro Banquete, Platão (2002) descreve o diálogo entre o personagem Sócrates e Diotima e apresenta as características daquele que se ocupa da Filosofia,

Oscila, igualmente, entre a sabedoria e a tolice; devido ao seguinte motivo: nenhum dos deuses, como é claro, exerce a filosofia, ou deseja ser sábio, pois que como deus já o é; quem é sábio não filosofa; não filosofa nem deseja ser sábio, também, quem é tolo - e aí reside o maior defeito da tolice: em considerar-se como alguma coisa de perfeito, conquanto, na realidade, não seja nem justa, nem inteligente. E quem não se considera incompleto e insuficiente, não deseja aquilo cuja falta não pode notar. [...] Eros é necessariamente um filósofo, e como tal ocupa o meio-termo entre o sábio e o tolo. (p. 145)

Isto é, estudar Filosofia é ser um peregrino, um andarilho a caminhar pelas estradas das incertezas, das dúvidas e, sobretudo, do questionamento permanente sobre as questões da existência e de todo o fazer humano.

[...] a atitude filosófica se inicia quando desconfiamos da veracidade ou do valor de nossas crenças cotidianas, desconfiança que surge, sobretudo, no momento em que nossas crenças, nossas ideias, nossos valores parecem contradizer-se uns aos outros. A filosofia é uma interrogação sobre o sentido e o valor do conhecimento e da ação, uma atitude crítica com relação ao que nos é dado imediatamente em nossa vida cotidiana, um trabalho do pensamento para pensar-se a si mesmo e da ação para compreender-se a si mesma. ${ }^{2}$

\footnotetext{
${ }^{1}$ Sobre a consciência mítica, consultar CAMPBELL, Joseph. 0 poder do mito. São Paulo: Palas Athena, 1990; ELIADE, Mircea. Mito e Realidade. São Paulo: Perspectiva, 2004.

2 Entrevista com Marilena Chaú, disponível em: https://revistacult.uol.com.br/home/entrevista-marilena-chauil. Acesso em 04 de agosto de 2019. 
O trabalho da Filosofia é a busca constante do sentido de toda a produção humana e, para isso, é necessário um mergulho em si mesmo. Esse mergulho pode ser associado ao mito de $\mathrm{Narciso}^{3}$, em cuja narrativa é interpretado comumente como símbolo da vaidade, do egocentrismo e da incapacidade de perceber os outros. No entanto, sabemos que uma das riquezas do mito é a possibilidade de ser interpretado de várias maneiras, que podem ser contrárias e contraditórias.

Em Narciso, visualizamos um rapaz lindo, encantador, que mergulha em busca da própria imagem refletida na água, que podemos vislumbrar como sendo o primeiro espelho. Escreve Chevalier e Greenbrant sobre a água, o espelho e o autoconhecimento: "[a] água serve de espelho, mas um espelho aberto sobre as profundezas do eu: o reflexo do eu, que aí se mira, trai uma tendência à idealização. Diante da água que reflete sua imagem, Narciso sente que ela não está acabada, que é preciso terminá-la." (CHEVALIER; GHEERBRANT, 1993, p. 630)

Em uma analogia ao mito, o trabalho da Filosofia se dá a partir do constante olhar para o espelho, ou seja, do exercitar a reflexão, isto é, do desdobrar sobre si mesmo nos moldes da frase escrita na entrada do Oráculo de Delfos: "conhece-te a ti mesmo". A frase "conhece-te a ti mesmo" está associada também ao filosofo Sócrates, o qual provoca o ser humano a pensar por si mesmo, buscar pelo autoconhecimento partindo da ironia e da maiêutica.

[...] atividade filosófica é o trabalho para interrogar e compreender o presente, dando-lhe respostas para que ele se compreenda a si mesmo. [...] filosofia é um trabalho do pensamento e que uma filosofia se exprime numa obra, ou seja, ela pensa e diz o que ainda não foi pensado nem dito e que, sem ela, não seria pensável nem dizível; ela interpreta o passado filosófico, interroga o presente cultural e abre um campo para o pensamento futuro, de maneira que ela nos insere em nosso próprio presente, quando somos capazes de apreender, simultaneamente, o que ela pensou e o que ela nos dá para pensar para além dela. ${ }^{4}$

É plausível considerar, a partir dos filósofos aqui trazidos para o diálogo, que é possível construir um conceito de Filosofia, tendo como ponto de referência tanto o olhar para si, num constante movimento de descoberta de si, como também um exercício constante de questionar e problematizar o mundo a nossa volta. No próximo tópico, vamos abordar o ensino da Filosofia.

\section{O Ensino de Filosofia}

\footnotetext{
${ }^{3}$ Sobre o mito de Narciso consultar BRANDÃO, Junito de Souza. Mitologia Grega. Petrópolis: Vozes, 1987, Volume II.

${ }^{4}$ Entrevista com Marilena Chauí, disponível em: https://revistacult.uol.com.br/home/entrevistamarilena-chauil. Acesso em 04 de ago.2019.
} 
O Ensino de Filosofia, além de ser um problema filosófico, ele apresenta em seu bojo questões práticas, operacionais, pedagógicas, ideológicas, fantasiosas, e, sobretudo, políticas. Perguntas como essas orientam a discussão sobre o ensino de Filosofia: o que é ensinar Filosofia no Ensino Médio? Como ensinar Filosofia no Ensino Médio? Qual a metodologia para o ensino da Filosofia no ensino médio? Por que ensinar Filosofia no Ensino Médio? Qual a importância dessa disciplina no Ensino Médio? São perguntas visíveis, no entanto, para além delas existem outras interrogações que decorrem de outros problemas para a pergunta. Ou seja, uma pergunta nunca é a pergunta anunciada, e sim o silêncio da elaboração com os seus barulhos subjetivos. Ainda é possível se fazer mais uma pergunta: é possível aprender Filosofia ou aprender a filosofar? O professor Cesar Augusto Ramos (2007), em uma proposta de discussão apresenta, em seu artigo "Aprender a filosofar ou aprender a filosofia: Kant ou Hegel?", esse mesmo problema, propondo também uma base para pensarmos.

Aprender a filosofar ou aprender a filosofia? Esta é uma questão que se põe de forma incontornável sobre as possibilidades do ensino da filosofia. Se essa tarefa é desejável, de imediato uma outra pergunta decorre: de que forma e mediante quais métodos ou instrumentos é possível aprender a filosofar ou aprender a filosofia? Estas questões não traduzem apenas uma preocupação pedagógica do ensino da filosofia, mas envolvem, também, uma forma de se pensar e de realizar a própria filosofia. (p. 197)

É comum encontrar em textos e no próprio Parâmetros Curriculares Nacionais (PCN's) afirmações que, segundo o filósofo Immanuel Kant, não é possível aprender filosofia, e sim filosofar. O pesquisador Éliton Dias da Silva (2013) apresenta em seu artigo A história da filosofia e o filosofar: um olhar a partir de Kant outra resposta a para pergunta, é possível aprender filosofia ou aprender a filosofar? O autor constrói um viés de interpretação para a pergunta e, em forma de crítica, a frase atribuída a Kant,

[...] o problema é que se trata de uma frase que não se encontra na obra do filósofo alemão e seja, talvez, uma interpretação incoerente com seu pensamento. [...] como se no ensino de filosofia a natureza da filosofia assegurasse a reflexão e a certeza do filosofar, tese contrária a filósofo de Konigsberg. Defende, ainda, um ensino que vá além da mera descrição dos conteúdos filosóficos, para o documento [...]. (p. 165)

Aprofundando ainda na reflexão, é pertinente ainda outra pergunta: o ensino da Filosofia centra sua atenção na história da Filosofia ou nos problemas da Filosofia? Para essa pergunta, a filósofa Marilena Chauí assume uma posição:

CULT - A senhora sempre afirmou a centralidade da história da filosofia para os estudos filosóficos. Atualmente, alguns professores têm defendido que a formação dos estudantes e docentes de filosofia, mais do que ensinar a história, deveria dar-se por um treinamento do ato de pensar. Como a senhora vê a questão hoje? 
MC - Houve um momento na história da filosofia em que se afirmou que não havia temas ou assuntos filosóficos e por isso não se poderia ensinar filosofia e sim ensinar a filosofar. Ou seja, considerou-se que a filosofia não possuía objeto próprio e não poderia, portanto, ser um saber transmissível, pois não haveria o que transmitir. ${ }^{5}$

É possível compreender, a partir da fala da filósofa, que o impasse acerca do processo centra-se sobre o que ensinar em Filosofia, ou seja, em sala de aula, no processo de ensino e de aprendizagem, o que necessariamente se ensina em uma disciplina de filosofia. Não é necessário inventar a roda, e sim entender o processo de como o ser humano pensou os problemas que the foram apresentados em momentos únicos da sua existência histórica. Dessa maneira, continua Chauí que

\begin{abstract}
Falo de um momento da história da filosofia justamente para deixar claro que é nela e com ela que podemos compreender porque alguns julgam que a filosofia poderia ser um treino do pensamento sobre qualquer objeto. Como você vê, precisamos recorrer à história da filosofia para entender posições acerca do ensino da filosofia. Por que a centralidade da história da filosofia? Em primeiro lugar, porque ela nos protege do risco de imaginar que estamos inventando a roda: há uma história de construção e transformação dos conceitos e não se pode supor que nosso pensamento esteja, a cada vez, partindo do zero. ${ }^{6}$
\end{abstract}

A Filosofia não é um saber que parte do nada, de um vazio, pois do nada não vem. A Filosofia é um saber sobre os problemas que a realidade apresenta, ela possui um método investigativo próprio, existe uma linguagem própria, e, sobretudo, uma atitude única em olhar e interpretar o mundo. Dessa maneira, estudar história da Filosofia implica conhecer uma estrutura de linguagem e método que "[...] nos protege do "achismo" ou do "eu acho que", pois ela nos coloca no campo do embate entre teorias, entre formas sistemáticas de exposição e interpretação, e não diante de um confronto entre opiniões injustificadas." ${ }^{7}$

Em contraposição a essa perspectiva, encontramos pesquisadores que compreendem o ensino de Filosofia como uma oficina de conceitos. Os pesquisadores Felipe Araújo e Filipe Ceppas (2017), em seu artigo $A$ aula de filosofia como oficina de criação, escreve que a

[...] função da filosofia não é a de repetir interpretações de mundo já propostas por filósofos ao longo de sua história. Filosofar é (...) criar conceitos. A tarefa do filósofo não é reprodução, mas invenção. Fazer filosofia é trabalhar com a criação, seja na proposição de novos conceitos que servirão para responder a

\footnotetext{
${ }^{5}$ Entrevista com Marilena Chauí, disponível em: https://revistacult.uol.com.br/home/entrevistamarilena-chaui/. Acesso em 04 de agosto de 2019.

${ }^{6}$ Entrevista com Marilena Chauí, disponível em: https://revistacult.uol.com.br/home/entrevistamarilena-chaui/. Acesso em 04 de agosto de 2019.

${ }^{7}$ Entrevista com Marilena Chauí, disponível em: https://revistacult.uol.com.br/home/entrevistamarilena-chaui/. Acesso em 04 de agosto de 2019.
} 
problemas e questões que se apresentam no horizonte, seja no pensar de maneira diferenciada problemas e conceitos sobre os quais os filósofos anteriores se debruçaram. Com isso, o exercício filosófico não exclui o estudo da História da Filosofia, mas este estudo também não pode ser entendido como centro do processo filosófico e do ensino-aprendizado da filosofia. ( p. 53)

Em suma, de acordo com os autores supracitados, a Filosofia pode ser compreendida como fábrica de conceito, em que pensar e sentir o mundo acontece medido por conceito, por marca ou por assinatura nele impregnado. Sob uma perspectiva de análise análoga, Silvio Gallo escreve que,

Primeiro, todo conceito é necessariamente assinado; cada filósofo, ao criar um conceito, ressignifica um termo da língua com um sentido propriamente seu. (...) A assinatura remete ao estilo filosófico de cada um, à forma particular de pensar e de escrever. "O batismo do conceito solicita um gosto propriamente filosófico que procede com violência ou com insinuação, e que constitui na língua uma língua da filosofia, não somente um vocabulário, mas uma sintaxe que atinge o sublime ou uma grande beleza". A partir disso, Alliez criou a bela imagem da filosofia como uma "assinatura do mundo": cada filósofo assina o mundo à sua maneira, por meio dos conceitos que cria. (GALLO, 2003, p.25).

É possível perceber que não existe uma Filosofia ou um único método de ensino de Filosofia. O que existe é a complexidade do ato de ensinar e as diversas concepções de Filosofia que são elaborações, questões pontuais e matérias as quais foram e são refletidas por pessoas de seu tempo e espaço. Por isso, quando se escolhe um método, uma abordagem para o Ensino da Filosofia e qual Filosofia ensinar, toma-se uma posição política no sentido lato da palavra: poder e mudança.

O próximo tópico será investigar as ementas da disciplina Filosofia nos cursos técnicos integrados no Instituto Federal - Campus Bambuí.

\section{O Ensino de Filosofia no Médio Integrado}

O Instituto Federal de Educação, Ciência e Tecnologia de Minas Gerais é uma instituição pública de ensino, integrante da Rede Federal de Educação Profissional e Tecnológica do Ministério da Educação, que oferta, principalmente, cursos técnicos e superiores e possui uma Reitoria (unidade administrativa) em Belo Horizonte/MG, além de campi em 18 cidades. $^{8}$

O campus Bambuí remonta sua história desde os anos 1949 e 1950, quando nasce a Fazenda Varginha, na qual funcionou o Posto Agropecuário em 1950, ligado ao Ministério da Agricultura. Em 1961, pela Lei 3.864/A, nasce a Escola Agrícola de Bambuí. Em 13 de fevereiro de 1964, a Escola foi transformada em Ginásio Agrícola pelo Decreto no 53.558 e, no dia 20 de agosto do "Ano da Agricultura" - 1968, o Decreto nº 63.923 elevou o Ginásio

\footnotetext{
${ }^{8}$ Informação encontrada no site: https://www2.ifmg.edu.br/portal/sobre-o-ifmg/o-que-e-o-ifmg.
} Acesso em 04 de agosto de 2019. 
à posição de Colégio Agrícola de Bambuí. Em 04 de setembro de 1979, o Decreto no 83.935 mudou a denominação de Colégio Agrícola para Escola Agrotécnica Federal de Bambuí - EAFBí. No ano de 2001, com o Programa de Expansão da Educação Profissional, a instituição firmou convênio com o Ministério da Educação em dezembro de 2008, ampliando ainda mais as possibilidades da educação técnica e tecnológica com a criação dos Institutos Federais. Dessa forma, a tradicional Escola de Bambuí foi elevada à posição de campus do Instituto Federal de Educação, Ciência e Tecnologia Minas Gerais - IFMG. Essa instituição foi criada pela Lei oㅜ 11.892, sancionada em 29 de dezembro de 2008, sendo uma autarquia formada pela incorporação da Escola Agrotécnica Federal de São João Evangelista, dos Centros Federais de Educação Tecnológica de Bambuí e de Ouro Preto e suas respectivas Unidades de Ensino Descentralizadas. ${ }^{9}$

Conforme a Lei no 11.892, de 29 de dezembro de 2008, que institui a Rede Federal de Educação Profissional, Científica e Tecnológica, cria os Institutos Federais de Educação, Ciência e Tecnologia tendo como um dos seus pilares a educação superior, básica e profissional conjugado com conhecimentos técnicos e tecnológicos com as suas práticas pedagógicas.

Os Institutos Federais são instituições de educação superior, básica e profissional, pluricurriculares e multicampi, especializados na oferta de educação profissional e tecnológica nas diferentes modalidades de ensino, com base na conjugação de conhecimentos técnicos e tecnológicos com as suas práticas pedagógicas, nos termos desta Lei. (...) I - ministrar educação profissional técnica de nível médio, prioritariamente na forma de cursos integrados, para os concluintes do ensino fundamental e para o público da educação de jovens e adultos. ${ }^{10}$

Pautado na legislação, o Instituto Federal de Minas Gerais, Campus Bambuí, busca atrelar a formação do indivíduo à perspectiva curricular nos conhecimentos técnicos e tecnológicos, trabalhando no nível médio integrado, que tem como foco a formação centrada na educação profissional tecnológica do sujeito.

O Campus Bambuí, além de possuir cursos técnicos subsequentes ao Ensino Médio, cursos de bacharelados e licenciatura e pós-Graduação (Lato Sensu), oferece também curso Técnico em Administração Integrado ao Ensino Médio, em Agropecuária Integrado ao Ensino Médio, em Informática Integrado ao Ensino Médio, em Manutenção Automotiva Integrado ao Ensino Médio, em Meio Ambiente Integrado ao Ensino Médio. São esses cursos técnicos integrados que oferecem a disciplina Filosofia, objeto de nossa análise.

Conforme os projetos pedagógicos dos cursos técnicos integrados, todos eles oferecem a disciplina Filosofia com natureza obrigatória, com uma

\footnotetext{
${ }^{9}$ Informação encontrada no site: http://www.bambui.ifmg.edu.br/portal/a-instituicao. Acesso em 04 de agosto de 2019.

10 Informação encontrada no site: http://www.planalto.gov.br/ccivil 03/ ato20072010/2008/lei//11892.htm. Acesso em 04 de agosto de 2019.
} 
aula semanal. Além disso, está presente nos três anos do ensino médio. Cada projeto de curso apresenta a disciplina Filosofia com especificidade, ou seja, as ementas dos cursos não são iguais. No entanto, existe curso que, em uma determinada série, apresenta ementas iguais.

Nos quadros abaixo, vamos investigar se as ementas contemplam o ensino da Filosofia centrado na História da Filosofia ou nos problemas de Filosofia.

Percebe-se, no quadro 01, que o curso Técnico Agropecuária Integrado entende que a disciplina Filosofia deve ser trabalhada centrando sua atenção nos problemas da Filosofia como Teoria do Conhecimento, Ética, Estética, Ciência Política, Felicidade, conceitos mais básicos da filosofia. A temática Ética aparece tanto na primeira série quanto na terceira série do curso.

Quadro 01: Curso Técnico Agropecuária Integrado/Disciplina Filosofia

\begin{tabular}{|l|l|l|}
\hline Série & Carga Horária & \multicolumn{1}{|c|}{ Ementa } \\
\hline $1^{\circ}$ & 40 horas & $\begin{array}{l}\text { Conceitos mais básicos da filosofia; estudo de temas } \\
\text { relacionados a três áreas importantes: Teoria do } \\
\text { Conhecimento, Ética e Estética. }\end{array}$ \\
\hline $2^{0}$ & 40 horas & $\begin{array}{l}\text { Primeiras teorias da Filosofia e principais filósofos da } \\
\text { antiguidade. }\end{array}$ \\
\hline $3^{0}$ & 40 horas & $\begin{array}{l}\text { Introdução às grandes questões da filosofia da atualidade; } \\
\text { Ética; Ética e Felicidade; Ciência Política. }\end{array}$ \\
\hline
\end{tabular}

Fonte: Elaborado com base no Projeto Pedagógico do Curso Técnico em Agropecuária Integrado ao Ensino Médio / 2015

No quadro 02, nossa análise centra-se nas ementas do curso Técnico Informática Integrado para compreender se contempla o ensino da Filosofia centrado na História da Filosofia ou nos problemas de Filosofia.

Quadro 02: Curso Técnico Informática Integrado/Disciplina Filosofia

\begin{tabular}{|l|l|l|}
\hline Série & Carga Horária & \multicolumn{1}{|c|}{ Ementa } \\
\hline $1^{\circ}$ & 40 horas & $\begin{array}{l}\text { Conceitos mais básicos da filosofia; estudo de temas } \\
\text { relacionados a três áreas importantes: Teoria do Conhecimento, } \\
\text { Ética e Estética. }\end{array}$ \\
\hline $2^{0}$ & 40 horas & $\begin{array}{l}\text { Introduzir o estudante no estudo das primeiras teorias da } \\
\text { Filosofia bem como os contatos com os principais filósofos da } \\
\text { antiguidade, ao mesmo tempo em que se promove o } \\
\text { aprimoramento de sua capacidade interpretativa e } \\
\text { argumentativa. }\end{array}$ \\
\hline $3^{0}$ & 40 horas & $\begin{array}{l}\text { Introdução às grandes questões da filosofia da atualidade; Ética; } \\
\text { Ética e Felicidade; Ciência Política. }\end{array}$ \\
\hline
\end{tabular}

Fonte: Elaborado com base no Projeto Pedagógico do Curso Técnico em Informática Integrado 2015.

O quadro 02 mostra a valorização nos problemas da Filosofia como Teoria do Conhecimento, Ética, Estética, Ciência Política, Felicidade, conceitos mais básicos da filosofia. A temática Ética aparece tanto na primeira série quanto na terceira série do curso. 
Encontra-se no quadro que as ementas da primeira série do curso Técnico Agropecuária Integrado e da primeira série curso Técnico Informática Integrado são iguais e, na terceira série, também. A diferença nas ementas está na segunda série onde o curso Técnico Informática Integrado centra sua atenção na sua capacidade interpretativa e argumentativa do estudante. Já o curso técnico Agropecuária Integrado pauta seu ensino de Filosofia nas primeiras teorias da Filosofia e nos principais filósofos da antiguidade.

O quadro 03 apresenta as ementas de Filosofia do curso Técnico Manutenção Automotiva Integrado que desenvolve seu ensino de Filosofia a partir dos problemas de Filosofia como lógica, retórica, persuasão, além de promover no estudante experiências de pensamento que o torne competente para uma leitura crítica e criativa da realidade urdida e tecida ao longo do tempo e ao largo do espaço. Na segunda série, a ementa é comum ao segundo ano do curso Técnico Agropecuária Integrado.

Quadro 03: Curso Técnico Manutenção Automotiva Integrado/Disciplina Filosofia

\begin{tabular}{|l|l|l|}
\hline Série & Carga Horária & \multicolumn{1}{c|}{ Ementa } \\
\hline $1^{\circ}$ & 40 horas & $\begin{array}{l}\text { Introdução à Filosofia, introdução à lógica, } \\
\text { introdução à retórica, introdução à persuasão. }\end{array}$ \\
\hline $2^{\circ}$ & 40 horas & $\begin{array}{l}\text { Primeiras teorias da Filosofia e principais filósofos } \\
\text { da antiguidade }\end{array}$ \\
\hline $3^{\circ}$ & 40 horas & $\begin{array}{l}\text { Desenvolver com o educando experiências de } \\
\text { pensamento que o torne competente para uma } \\
\text { leitura crítica e criativa da realidade urdida e tecida } \\
\text { ao longo do tempo e ao largo do espaço. }\end{array}$ \\
\hline
\end{tabular}

Fonte: Elaborado com base no Projeto Pedagógico do Curso Técnico em Manutenção Automotiva Integrado ao Ensino Médio / 2015

O curso Técnico Administração Integrado, como pode ser encontrado no quadro 04, tem a ementa da segunda série igual à do curso Técnico Manutenção Automotiva Integrado, Técnico Agropecuária Integrado. A ementa da primeira série é igual à dos cursos Técnico Informática Integrado e Técnico Agropecuária Integrado. O ensino de Filosofia também está pautado no ensino de Filosofia por problemas filosóficos.

Quadro 04: Curso Técnico Administração Integrado/Disciplina Filosofia

\begin{tabular}{|l|l|l|}
\hline Série & Carga Horária & \multicolumn{1}{c|}{ Ementa } \\
\hline $1^{\circ}$ & 33,2 horas & $\begin{array}{l}\text { Conceitos mais básicos da filosofia; estudo de } \\
\text { temas relacionados a três áreas importantes: Teoria } \\
\text { do Conhecimento, Ética e Estética. }\end{array}$ \\
\hline $2^{0}$ & 33,2 horas & $\begin{array}{l}\text { Primeiras teorias da Filosofia e principais filósofos } \\
\text { da antiguidade. }\end{array}$ \\
\hline $3^{\circ}$ & 33,2 horas & $\begin{array}{l}\text { Introdução às grandes questões da filosofia da } \\
\text { atualidade; Ética; Ética e Felicidade; Igualdade e } \\
\text { diferença: o pensamento multicultural. Filosofia e }\end{array}$ \\
\hline
\end{tabular}


meio ambiente.

Fonte: Elaborado com base no Projeto Pedagógico do Curso Técnico em Administração Integrado ao Ensino Médio / 2016.

Conforme o quadro 05, o curso Técnico Meio Ambiente Integrado centra no ensino de problemas da Filosofia e apresenta a ementa da primeira série igual aos cursos Técnico Administração Integrado, Técnico Agropecuária Integrado e Técnico Informática Integrado. As ementas da segunda série são semelhantes aos cursos Técnico Administração Integrado, Técnico Manutenção Automotiva Integrado, Técnico Agropecuária Integrado.

Quadro 05: Curso Técnico Meio Ambiente Integrado/Disciplina Filosofia

\begin{tabular}{|l|l|l|}
\hline Série & Carga Horária & \multicolumn{1}{|c|}{ Ementa } \\
\hline $1^{\circ}$ & 40 horas & $\begin{array}{l}\text { Conceitos mais básicos da filosofia; estudo de } \\
\text { temas relacionados a três áreas importantes: Teoria } \\
\text { do Conhecimento, Ética e Estética. }\end{array}$ \\
\hline $2^{\circ}$ & 40 horas & $\begin{array}{l}\text { Primeiras teorias da Filosofia e principais filósofos } \\
\text { da antiguidade. }\end{array}$ \\
\hline $3^{\circ}$ & 40 horas & $\begin{array}{l}\text { Introdução às grandes questões da filosofia da } \\
\text { atualidade; Ética; Ética e Felicidade; Igualdade e } \\
\text { diferença: o pensamento multicultural. Filosofia e } \\
\text { meio ambiente. }\end{array}$ \\
\hline
\end{tabular}

Fonte: Elaborado com base no Projeto Pedagógico do Curso Técnico em Meio Ambiente Integrado ao Ensino Médio / 2014

A terceira série desse curso apresenta uma peculiaridade na formação do estudante onde a ementa apresenta o pensamento multicultural e a relação entre Filosofia e meio ambiente.

\section{Considerações Finais}

Após o processo de comparação entre as ementas dos cursos integrados de Ensino Médio do IFMG/ Campus Bambuí, é possível considerar que cada curso, mesmo com suas peculiaridades, construiu a disciplina de Filosofia centrado na proposta de um ensino de Filosofia a partir de problemas filosóficos com questões que envolvem a Teoria do Conhecimento, da Ética, da Estética, da Ciência Política e da Felicidade. Ou seja, apresentam uma base comum.

No entanto, mesmo o curso tendo suas bases na educação profissional tecnológica, tal como suas diretrizes orientam, não encontramos, nas ementas analisadas e nas bibliografias indicadas como referenciais, orientações para trabalhar o conceito ou a temática técnica, tecnologia e trabalho, apresentando, com isso, certa discrepância entre as diretrizes da Instituição e as disciplinas pertencentes do Ensino Médio Integrado. 
Sabemos que o currículo ensino médio integrado tem como eixo transversal ${ }^{11}$ o conceito de trabalho como princípio educativo (PRATES, BRAGA, 2019). Não consideramos trabalho como sinônimo de emprego, mas trabalho como perspectiva ontológica. Sendo o Instituto Federal uma instituição focada na técnica e na tecnologia, as ementas de Filosofia não contemplaram a discussão acerca da técnica e da tecnologia.

\section{Referências}

ARAÚJO, Felipe; CEPPAS, Filipe. A aula de filosofia como oficina de criação. In: Revista Ideação. Edição especial, 2017. Disponível em: file:///C:/Users/Janaina/Downloads/2986-12363-1-PB\%20(1).pdf. Acesso em 04 de agosto de 2019.

BRANDÃO, Junito de Souza. Mitologia Grega. Petrópolis: Vozes, 1987, Volume II.

BRASIL, Lei no 13.145, de 16 de fevereiro de 2017. Altera a Leis no 9.394, de 20 de dezembro de 1996, que estabelece as diretrizes e bases da educação nacional.

BRASIL, Lei no 9.394, de 20 de dezembro de 1996. Estabelece as diretrizes e bases da educação nacional. Diário Oficial da União, Brasília, DF, 23 dez. 1996.

BRASIL, Ministério da Educação, (1998). Parâmetros Curriculares Nacionais para o Ensino Fundamental. Brasília, MEC/SEF.

BRASIL, Ministério da Educação, (1999). Parâmetros Curriculares nacionais - ensino médio. Brasília: MEC/SEMT.

CAIS, J. Metodología del análisis comparativo. Madrid: Centro Investigaciones Sociológicas, 1997.

CAMPBELL, Joseph. O poder do mito. São Paulo: Palas Athena, 1990.

CHEVALIER, Jean; GHEERBRANT, Alain. Dicionário de símbolos. $7^{a}$ ed. Rio de Janeiro: José Olympio, 1993.

CIAVATTA, Maria. Trabalho como princípio educativo. Artigo - Ano 2009. Dicionário da Educação Profissional em Saúde. Fundação Oswaldo Cruz. Escola Politécnica de Saúde Joaquim Venâncio. Rio de Janeiro - RJ, 2009.

CIAVATTA, Maria; RAMOS, Marise. Ensino médio e educação profissional no Brasil, dualidade e fragmentação. Artigo - Ano 2011. Revista Retratos da

\footnotetext{
${ }^{11}$ Ideia inspirada nas conversas com o professor Bergston Luan Santos (2018/2019) do Instituto Federal de Educação, Ciência e Tecnologia do Norte de Minas Gerais/ IFNMG Campus Salinas.
} 
Escola, Brasília, v. 5, n. 8, p. 27-41, jan.jun., 2011. Disponível em: $<$ http//www.esforce.org.br>. Acesso em: 5 abr. 2019.

ELIADE, Mircea. Mito e Realidade. São Paulo: Perspectiva, 2004.

GALLO, Silvio. Deleuze \& a Educação. Belo Horizonte: Autêntica, 2003.

KOHAN, Walter Omar; GALLO, Sílvio. (Orgs). Filosofia no ensino médio. Petrópolis: Vozes, 1999.

Ministério da Educação. Base nacional comum curricular. Brasília, DF: MEC, 2015.

PLATÃO. Apologia de Sócrates. Banquete. São Paulo: Marin Claret, 2002.

PRATES, Admilson Eustáquio. Filosofia no processo seletivo: análise educacional de editais e suas bases. Legais / Revista Intercâmbio - vol. IX 2017/ISNN - 2176-669X, 2017.

PRATES, Admilson Eustáquio. O Fazer Filosófico. Montes Claros/MG: Unimontes, 2006.

PRATES, Admilson Eustáquio. Sala de espelhos: inquietações filosóficas. Montes Claros/MG: Unimontes, 2009.

PRATES, Admilson Eustáquio; BRAGA, Osório Esdras Guimarães. O trabalho como princípio educativo no ensino médio integrado. In: Revista de educação, ciência e tecnologia do IFAM. ISSN-E: 2238-4286 Vol. 13 - № 1 - Junho, 2019.

Projeto pedagógico do curso técnico em administração integrado ao ensino médio. Disponível em http://www.bambui.ifmg.edu.br/portal/images/PDF/PPC_T\%C3\%A9cnico_em Administra\%C3\%A7\%C3\%A3o_alterado_de_acordo_com_novo_regulamento _de_est\%C3\%A1gio.pdf. Acesso em 01 de jul de 2019.

Projeto pedagógico do curso técnico em agropecuária integrado ao ensino médio. Disponível em

http://www.bambui.ifmg.edu.br/portal/images/PDF/Cursos/BIIAGRO/PPC_T\%C3\%A9cnico_-_Agropecu\%C3\%A1ria_-_Integrado.pdf. Acesso em 01 de jul de 2019.

Projeto pedagógico do curso técnico em informática integrado ao ensino médio. Disponível em

http://www.bambui.ifmg.edu.br/portal/images/CURSOS/BIIINFO/PPC_-

_T\%C3\%A9cnico_-_Inform\%C3\%A1tica_-_Integrado.pdf. Acesso em 01 de jul de 2019.

Projeto pedagógico do curso técnico em manutenção automotiva integrado ao ensino médio. Disponível em http://www.bambui.ifmg.edu.br/portal/images/PDF/Cursos/BIIMAUT/PPC_- 
_T\%C3\%A9cnico_-_Manuten\%C3\%A7\%C3\%A3o_Automotiva__Integrado.pdf. Acesso em 01 de jul de 2019.

Projeto pedagógico do curso técnico em meio ambiente integrado ao ensino médio. Disponível em

http://www.bambui.ifmg.edu.br/portal/images/PDF/Cursos/BIIMAMB/PPC_T\% C3\%A9cnico_em_Meio_Ambiente_Bambu\%C3\%AD.pdf. Acesso em $01 \mathrm{de}$ jul de 2019.

RAMOS, Cesar Augusto. Aprender a filosofar ou aprender a filosofia: Kant ou Hegel. In: Trans/Form/Ação. São Paulo, 30(2): 197-217, 2007. Disponível em: http://www.scielo.br/scielo.php?script=sci_arttext\&pid=S010131732007000200013. Acesso em 04 de agosto de 2019.

SILVA, Éliton Dias da. A história da filosofia e o filosofar: um olhar a partir de Kant. In. Revista Filogênese - Revista Eletrônica de Pesquisa na Graduação em Filosofia da UNESP. Vol. 6, $n^{\circ} 2$, 2013. Disponível em:

www.marilia.unesp.br/filogenese. Acesso em 04 de agosto de 2019. 